\title{
Steven Farmer: Strange Chemistry: The Stories Your Chemistry Teacher Wouldn't Tell You
}

\author{
Edward R. Adlard ${ }^{1}$
}

๑) Springer-Verlag GmbH Germany, part of Springer Nature 2017

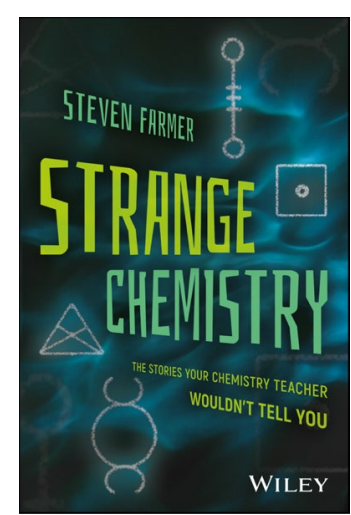

Bibliography

The Stories Your Chemistry Teacher

Wouldn't Tell You

Steven Farmer

Wiley, Hoboken, NJ, USA, 2017,

pp xvii +346

ISBN 978-1-119-26526-9

EUR 53.40, GBP 44.50

Behind every chemist is a teacher who, by their enthusiasm, has made the subject interesting to his or her pupils. Dr. Farmer is such a teacher who has gone to great pains to make his subject relevant to his audience. None of the material in the book is original but has been gathered together from a variety of sources into a coherent whole. The author has composed over a hundred articles on various topics across the whole spectrum of chemistry ranging from the initial chapter on the nature of the chemical bond to the composition of road asphalt. He has come up with some extraordinary data such as that the world consumes 40,000 tons of aspirin a year and 300,000 people commit suicide using aluminium phosphide. Fortunately not many people in the UK, apart perhaps from David Attenborough and his crew, are likely to encounter the golden poison-dart frog, the fascinating chemistry of which is described in Chapter 3. There is a preponderance of articles relating to drugs, both legal and illegal, for reasons that the author makes clear in the foreword. The misuse of drugs is a problem in the UK but clearly it is an even greater problem in the US. The author is from California so, although there is a lot of information about acetaminophen, you will not find the word "paracetamol" (its UK name) anywhere. There are some surprising omissions, for example no reference to cannabis and, considering the author's location, nothing about wine. In the chapter on explosives, he gives an equation for the decomposition of gunpowder and from this one can see that before the advent of modern propellants the phrase "the fog of war" was literally true. Many of the articles have quite complex theoretical explanations but he has missed an opportunity in the explosives chapter to explain why TNT has such a relatively low melting point, an important practical point since it can be melted by steam heating.

In spite of the US bias, it would be churlish of me to criticize this book which is one that should be possessed by every chemistry teacher and I cannot recommend it too highly.
Edward R. Adlard

e.adlard77@btinternet.com

1 Burton, UK 